\title{
The Implementation of Contextual Learning in Improving the Quality of Motor Development Course for PETE Students
}

\author{
Agus Mahendra*, Nuryadi Nuryadi, Lukmanul Hakim Lubay, Mesa Rahmi Steppani \\ Department of Sport Education, Faculty of Sport and Health Education \\ Universitas Pendidikan Indonesia \\ Bandung, Indonesia \\ *agus_mahendra@upi.edu
}

\begin{abstract}
Learning a theoretical lesson with so many contents related to facts and information like the course of "Children Motor Development," can be so boring and non-motivating to the students. From repeated experiences, it can be observed that the class atmosphere is mostly relatively passive and characterized by low students; enthusiasm. The purpose of this research was to find the best solution on what learning model should be employed to improve the quality of learning processes and results, fit into the characteristics of the course. Finally, the teaching team chose one learning model called contextual learning (CTL) that relies on 7 to 8 steps to be implemented, all of which are directed to provide deep meaning to the brain and the way students think. To do that, the $R$ and $D$ method was chosen and a certain modified steps were followed. The results was satisfactory for the class atmosphere was getting better and almost all students made positive comments that they enjoy the learning situation and they enthusiastically involved in all learning step to accomplish their projects.
\end{abstract}

Keywords-motor development; physical education teacher education (PETE); contextual learning

\section{INTRODUCTION}

This research is related to one innate problem in the learning process in higher education, especially related to subject that is mostly consisting of theoretical content [1] that should be learned by heart by the physical education teacher education (PETE) students, that is Children Motor Development [2]. This course is a compulsory course offered in PETE for Elementary schools study programs in third semester $[3,4]$. The aim of this course is to equip teacher candidates with a series of knowledge and skills related to the pattern of children motor development.

The subject of Motor Development is theoretical, describing various stages of motor development and its acquisition from early birth to toddler, children and adolescents [5]. The substance is mainly related to the child's physical and motoric development process, and there are so many characteristics and facts that must be remembered and memorized as prove that students already mastered its content. With the old ways of teaching and lecturing, this course is seen as unattractive course to students. As a result, the class atmosphere is relatively monotonous; characterized by less discussion or even poor reflective process.

Based on all these problems, the teaching team of this course began to search, opening literature and consulted experts. It was realized that the nature of the subject matter was intrinsically containing weaknesses in nature, especially for the generation of "NOW" students. One of the considerations that emerged was that the theoretical nature of the course must be transformed into a learning task containing rich context that can be implemented. Therefore, the workings of the contextual learning model (CTL) immediately attracted the attention of researchers [6]. The question posed in this study was, how the contextual model in the Motor Development course help students to achieve better learning outcomes?

As acknowledged by experts, the contextual model is a learning system based on the philosophy that students are able to absorb lessons when they capture the meaning in the academic material they receive and associate new information with the knowledge and experience they had before. Why does this CTL apply that way? Experts claim that CTL is able to satisfy the brain's need in associating new information with existing knowledge that stimulates the formation of the physical structure of the brain in order to respond to the environment [7].

CTL consists of eight components, namely: making meaningful connections, independent learning, doing meaningful work, collaborating, critical and creative thinking, helping individuals to grow and develop, achieving high standards, and using authentic judgments [7]. By Alwasilah (in Johnson), the eight components were summarized into seven application steps, namely, 1) problem-based teaching, 2) using diverse contexts, 3) considering the diversity of students, 4) empowering independent learning students, 5) collaborative learning, 6) the use of authentic assessment, and 7) establishing high standards to be achieved together [7]

Many experts argue that the decisions that teachers make when choosing assignments are very important. Christiansen argued that learning tasks which are the focus of student work and problem solving not only determine the level of thinking of 
students, but also the nature of the relationship between teacher and student [8].

Furthermore, Francisco and Maher state that giving students the opportunity to work on complex tasks, rather than solving a series of problems that are easier, improves mathematical and logical reasoning in students [9]. In a study of fourth and sixth grade students' mathematical reasoning in an urban school district in the United States, found that carefully designed assignments allowed students to think effectively and in a targeted manner, and "help them learn to use various arguments when they are involved in learning". Mueller, Yankelewitz, and Maher argued that careful attention must be given to the presentation of tasks, as well as various learning opportunities that they provide [10].

On this basis, the teaching team of this course have been initiated a research and development program to improve the quality of learning process and its results by implementing the 7 steps that are recognized as effective in directly involving brain modalities in learning.

\section{METHOD OF RESEARCH}

\section{A. Research Objectives}

This study aimed to find and formulate best practices in learning "motor development" courses that is effective in improving learning outcomes. Participants of this course were the third semester of Physical Education Teacher Education (PETE) students for elementary school students, who were involved in a series of lecture programs using a contextual model. To realize this goal, a step of development research have been taken that can ensure the changing learning conditions of the subjects targeted by the study. The steps taken in the application of the contextual model are directed at giving meaning to learning, in the form of understanding and in the form of utilizing this course in their academic competencies.

The specific objectives of this study are as the followings:

- Develop a contextual learning model and set the steps for its implementation with operational steps at each stage and episode of learning to improve the meaningfulness of the material being studied by the participating students.

- Providing equipment and opportunities for students to always give positive meaning to learning material and the learning process.

- Establish authentic assessment steps, which in addition to monitoring the development of student learning outcomes, it also to support efforts to give positive meaning in helping students master the overall learning material.

\section{B. Research Approaches and Methods}

In accordance with the objectives of the research in producing a formula or steps for best practices in improving the quality of learning, the research approach chosen is to use a research and development model (R \& D). This approach is certainly used in a concise version and modified to a certain degree to meet the demands of development. The proposals to be applied in the model includes:

- To expand the course content scope more broadly, to open the possibility to be used and studied by students as two related variables between the growths of physical with the development of motor competencies of the children.

- As the consequence, this course will provide students to learn and develop skills in using the measurement instrument, in order to encourage the study program to provide laboratories facilities and equipment needed to measure anthropometric component and motor development measurement.

- The main courses are directed at developing understanding, skills and abilities of research practices in the field of physical anthropometrics and motor development, combined with exploring research methodologies and deepening theories in the fields of anthropometrics and motor development.

- The destination of this course for each student is to produce skills of conducting research in the field of physical growth and motor development of children, related to various health-associated contexts such as nutrition, health, fitness, triadic health school program, and family background. All of these skills were focused on improving the academic writing skills in form of composing articles for publication in journals or in conference proceedings.

There must be a portion of providing initial products such as teaching materials, manual handbooks of the labs equipment, measurement forms, collection and translation of necessary instruments such as TGMD2, article templates that must be produced by students, and evaluation equipment.

\section{RESULT AND DISCUSSION}

\section{A. Result}

Result of this research consisting of two group of results; firstly result of the development program related to products needed in the class of the course, and secondly result related the effect of this course on PETE students' behavior during the class using the contextual model.

1) Development results: The results of this study are classified into two different results; one is tangible output and second is intangible outcome. The tangible output comprise of:

- The availability of the book draft of teaching materials for the course "Children Growth and Motor Development," in the form of draft that is ready to be published, minus pictures or accompanying illustrations.

- The availability of printable of anthropometric and TGMD2 measurement and manual and those forms to be employed in the measurement program, 
- The availability of anthropometric measuring equipment purchased before and during the research progress for which these equipment will be donated and become the property of the Laboratory of Children Development built by the Study Program, and the decree of this labs' personal appointment already issued by the faculty Dean.

- Manual implementation for the lectures on implementing this "Children Growth and Development" courses in the next semester program that supposed to be in accordance with the steps of applying the contextual learning model.

2) Learning outcome result:

- The level of students involvement in the lecture program was relatively high, both in the theoretical lesson in the classroom and practicum program in the laboratory, practicum in the measurement process in schools, and practicum in writing the academic paper and report regarding the growth and development profile of elementary school children in Bandung city and its regions.

- The level of understanding and the scope of their understanding was relatively higher than that from the earlier class, especially when examined by the higher order thinking test format using a combination of objective and essay test.

- The level of products generated by PETE students such as paper, anthropometric reports, and article for journals also reflected a better quality, ranging from average and above average, when they were graded by the common criteria employed in the evaluation process.

\section{B. Discussion}

The study investigated the effect of the CTL model on students' learning outcome on Motor Development course. To implement this CTL model, the researcher needed to provide variety of material and learning medias, needed or required by the model in order for the model to be properly working. As has been mentioned in the introductory section, the CTL model necessitated seven steps that should be gone through in applying this model, they are: making meaningful connections, independent learning, doing meaningful work, collaborating, critical and creative thinking, helping individuals to grow and develop, achieving high standards, and using authentic judgments.

The result from the development process (result of group 1) were basically in order to make all the materials to be meaningful for the students, so the learning with contextual features could be happening. With all those materials presented in a manner of contextual way and all scenarios for the lesson according to the model demand, then the lesson could be categorized as the contextual model implementation.

The results from the assessment and observation revealed that in the first phase, there were many negative response from the students, given the facts that they feel too much obliged for the lesson. Just in the beginning of the lesson program, the class seemed so reluctant to get actively involved both in finding the problems identification and in the solution seeking. Yet, after the intervention program, most of them were categorized as possessing a high level of higher learning involvement. More specifically, in the first phase, most students were amazed with so many targets set up by the lecturer team.

In order for the class to get a meaningful activities during the lesson, researcher or lecturer team have made a lot of way in making a problems solving style and working in group in the teaching. Most students did not go through all the stages of problem-solving situations in order to find alternative solutions, even though the researchers informed the group that there was more than one correct solution. This however may stem from a lack of specific knowledge of the course of motor development and its stages.

In the second phase, the students started to pay more attention to the goal of the lesson, activating prior knowledge in order to solve it successfully. The students monitored their own group work while planning for a solution, carried out their plan and checked the validity of solutions. According to Schoenfeld, in a problem-solving situation, students possessing high metacognitive awareness have a greater ability to divide their time between understanding the problem at hand and then planning a solution to surmount it [11]. This is then substantiated by an increased cognizance of 'next-play' decision-making. The increased ability to execute successfully is based on that decision- making, and then if the decisions are not satisfying, being reactive enough to reach alternative solutions.

Therefore, one can conclude that the problem solving approach that delivered by the researcher in the lesson have helped students to become more strategic and autonomous learners. The CTL model gave the students the opportunity to get involved in implicit learning while problem solving. Its situation combined with factors such as more challenging environment, and contextualized problems all enabled students to pay more attention to the demand of the lesson, by implication, enhance their procedural knowledge and conditional knowledge [12]. The findings from this work are consistent with the suggestions from other researchers who claim that the CTL approach promotes metacognitive elements such as declarative and procedural knowledge [13].

During the intervention program students were encouraged to check factors (i.e. finding facts, more attentive to the suggestion, cohesion of teammates, etc.), plan their actions, analyze their thoughts and explain why they chose those solutions [14]. When their solutions were wrong they had to reflect on their own mistakes in order to rethink and re-plan their actions [15]. Therefore, students developed cognitive strategies and skills, which must be present when metacognitive strategies are employed in problem-solving situations [16]. Again, according to Chatzipanteli et al., students with a high metacognition understand the importance of cognitive strategies; they make associations between information, and are able to monitor, evaluate and regulate their cognitive activities [12]. 
In other situation, the guided discovery questions during the learning process also helped students to generate their own meaningful questions. These questions centered on such problem-solving variables as how to measures and how the relationship between the collected data, more generically, the structural 'aim of the measurement'; directed their thinking to a more external focus. The teacher-led discussions permitted a greater involvement within the lesson, mobilizing the students for self-questioning, a cognitive comprehension strategy [17] which, by implication, guided them to monitor their interaction and, by implication, discover effective solutions for both the mingling problems. Our findings are consistent with the notion that learning-by-discovery and learning-by-doing tasks encourage students to activate their thinking processes [18].

Additionally, when working in groups the students had the opportunity to listen to other points of view and rethink their own actions. They became active participants in their own learning process because they could control and modify their own ideas according to others' notions and ideas. The contextual model created an environment for students to learn from their teacher and collaboratively from each other. Perhaps their higher cognitive abilities offered those clues to help one another, discussing strategies and methods to complete tasks successfully [19]. This is perhaps the reason why students documented better products such as paper and article to be published. Underpinning our findings is the central point that as a result of developing a meaningful content and materials for the learning process, this model has proven itself as the one that worked well on student's perspective.

In summary, the results of the study have proven that the contextual approach could enhance students' learning outcomes, both in theoretical comprehension and also in more practical skills related to growth and development of children. These students acquire the ability to solve problems for themselves in real-life situations. However, relatively few lecturers use such contextual approaches in the class. Maybe it is good for our students to pay more attention to these contextual steps, which encourage them to acquire better learning behavior that leads to greater engagement in the whole lesson and discussion [20].

It 'is irrefutable that one of the cornerstone goals of growth and development course from a holistic perspective is to enable students to become increasingly more knowledgeable and autonomous learners who will choose to implement it in the later phase of their life when they are becoming reflective teachers. Of course, further research is needed to verify all the results in fully contextual situations, and an extension to this research might be to actuate the model into other course and compare results.

It's clear that from the micro perspective, the development of the model requires the availability of media and supporting tools. It should also be supported by the policy system that requires the presence of a children-development laboratory, in which students can develop such related competencies as anthropometric and basic motor development measurement. In terms of ideas, a proposal has already been submitted to the head of the PETE program. As part of the efforts, part of the research grant were also subsidized to the procurement of equipment.

Student experiences in mastering measurement techniques and collecting anthropometric data, basic motor skills and analyzing processes of the developments quality such as aerobic-anaerobic capacity, bio motor capacity and motor abilities, have made students felt satisfied and enjoyed the true meaning of competencies provided in related subjects.

Likewise, from the macro perspective, the result of this research should become a vehicle to gain and grab great opportunity to develop children growth and motor development disciplines as one of the field study in developing the state of the art of the discipline of sport sciences. Therefore, the substance and nature of this course requires modification in the curriculum structure level of the PETE Study Program and, as the consequence, it also requires changes in the syllabus and lesson planning level.

Therefore, the urgency of this research is surmounted in the concern not only to improving the quality of learning, but also in the development of applied competencies in the fields of physical education and physical activities. To a certain extent, this research is giving a way to an effort to develop one of the delivery systems in the academic field within the PETE for Elementary School study program. This needs to be seriously prepared to encourage the occurrence of a positive climate for the improvement of other courses, by seeking the development efforts.

\section{CONCLUSIONS}

The results of this study suggested that most of the participants were strongly agreed that they were exactly influenced by the way the lesson presented by the lecturers, and it has given much impact on their comprehension to the substance of the lesson. They showed a level of appreciation that they have mastered so many skills that they think strongly valuable to their future carrier as PE teachers having additional competencies in measuring children anthropometric dimension and skill acquisition as well as level of motor development. They greatly acknowledge that such competencies are highly important in their future carrier, both as teachers and also as growth and development practitioners. From those acknowledgement and from the fact that so many valuable products this study have elicited, there's no doubt that the CTL model implementation in theoretical subject matter has been effective and need to be implemented by many lecturers in many subject matters. A further study needs to be conducted in other aspect of implementation, to elicit a stronger evidence of its effectiveness.

\section{ACKNOWLEDGMENT}

The researchers are highly indebted to the decision making personals who have made this research possible to be conducted and therefor the researcher would like to extent a sincere great gratitude to the director of research and society services center (LPPM) of UPI who have provided the fund for the research expenses in the academic year of 2018. 


\section{REFERENCES}

[1] G. Nyberg, "Developing a 'somatic velocimeter'-the practical knowledge of freeskiers," Qualitative Research in Sport, Exercise and Health, vol. 7(1), pp. 109-124, 2015

[2] N. McEvilly, M. Verheul, M. Atencio, and M. Jess, "Physical education for health and wellbeing: a discourse analysis of Scottish physical education curricular documentation," Discourse: Studies in the Cultural Politics of Education, vol. 35(2), pp. 278-293, 2014.

[3] F.C. Chambers and K.M. Armour, "Do as we do and not as we say: teacher educators supporting student teachers to learn on teaching practice," Sport, Education and Society, vol. 16(4), pp. 527-544, 2011.

[4] F. Herold and M. Waring, "Is practical subject matter knowledge still important? Examining the Siedentopian perspective on the role of content knowledge in physical education teacher education," Physical Education and Sport Pedagogy, vol. 22(3), pp. 231-245, 2017.

[5] V. Đorđić, T. Tubić, and D. Jakšić, "The relationship between physical, motor, and intellectual development of preschool children," ProcediaSocial and Behavioral Sciences, vol. 233, pp. 3-7, 2016.

[6] D. Clarke and A. Roche, "Using contextualized tasks to engage students in meaningful and worthwhile mathematics learning," The Journal of Mathematical Behavior, vol. 51, pp. 95-108, 2018

[7] E.B. Johnson, Contextual teaching and learning: What it is and why it's here to stay. Corwin Press, 2002

[8] B. Christiansen, A.G. Howson, and M. Otte (Eds.). Perspectives on mathematics education. Dordrecht, Holland: Reidel, 1986, pp. 243-307.

[9] J.M. Francisco, and C.A. Maher, "Teachers attending to students' mathematical reasoning: Lessons from an after-school research program," Journal of Mathematics Teacher Education, vol. 14, pp. 4966, 2011.

[10] M.F. Mueller, D. Yankelewitz, and C. Mayer, "Promoting student reasoning through careful task design: A comparison of three studies,'
International Journal for Studies in Mathematics Education, vol. 3, pp. $135-156,2010$

[11] A.H. Schoenfeld, "What's All the Fuss about Metacognition?," Cognitive Science and Mathematics Education, pp. 189-215, 1987.

[12] A. Chatzipanteli, N. Digelidis, C. Karatzoglidis, and R. Dean, "A tactical-game approach and enhancement of metacognitive behaviour in elementary school students," Physical Education and Sport Pedagogy, vol. 21(2), pp. 169-184, 2016.

[13] D. Kirk and A. MacPhail, "Teaching games for understanding and situated learning: Rethinking the Bunker-Thorpe model," Journal of Teaching in Physical Education, vol. 21, pp. 177-92, 2002.

[14] M. Gosper and D. Ifenthaler, Curriculum Models for the 21st Century, New York, 2014.

[15] W. Briki, "Rethinking the relationship between momentum and sport performance: Toward an integrative perspective," Psychology of Sport and Exercise, vol. 30, pp. 38-44, 2017

[16] P.I. Webb and P.J. Pearson, "An integrated approach to teaching games for understanding (TGfU)," 1st Asia Pacific Sport Educ Conf, pp. 1-11, 2008.

[17] M. Wu, X. Liang, S. Lu, and Z. Wang, "Infant motor and cognitive abilities and subsequent executive function," Infant Behav Dev, vol. 49(23), pp. 204-13, 2017.

[18] J. Quay, J. Kokkonen, and M. Kokkonen, "Finnish interpretations of Creative Physical Education," Asia-Pacific J Heal Sport Phys Educ, vol. 7(2), pp. 173-90, 2016.

[19] M.A. Whitley, E.M. Wright, and D. Gould, "Coaches' perspectives on teaching life skills to underserved South African children and youth," International Journal of Sports Science \& Coaching, vol. 11(3), pp. 312326, 2016.

[20] B. Moy, I. Renshaw, and K. Davids, "Variations in acculturation and Australian physical education teacher education students' receptiveness to an alternative pedagogical approach to games teaching," Physical Education and Sport Pedagogy, vol. 19(4), pp. 349-369, 2014. 